

$$
\begin{aligned}
& \sum_{1033} \\
& 18.963 \\
& 19162 \\
& \text { CHM }
\end{aligned}
$$

$$
\begin{gathered}
\text { THE DAVIS PRESS } \\
\text { WORCESTER, MASSACHUSETTS }
\end{gathered}
$$





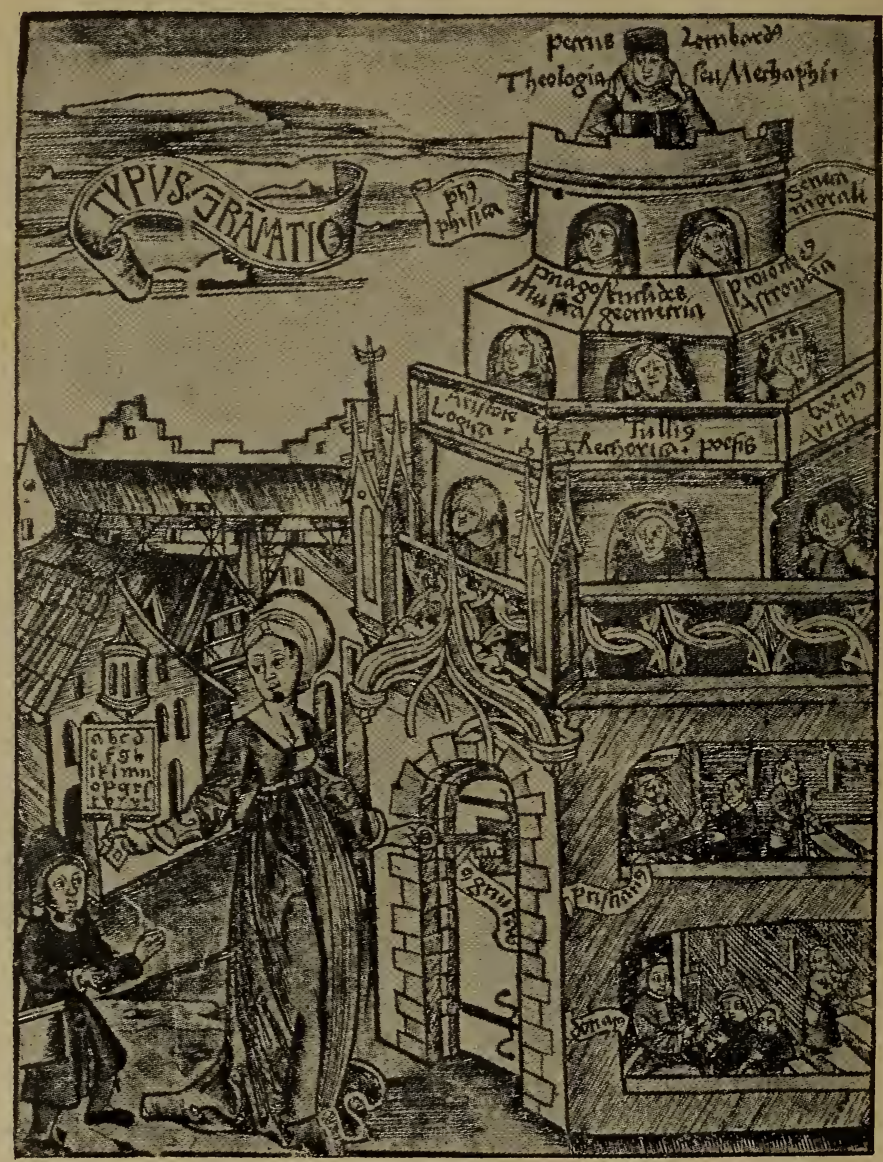

Figure 2 


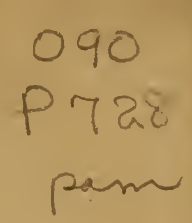

\title{
THE HORNBOOK AND ITS USE IN AMERICA
}

\author{
BY GEORGE A. PLIMPTON
}

In treating of the history and use of the hornbook in America, it is necessary first to study the history of the hornbook in the old world. The hornbook, in point of fact is not a book at all. Originally it was a piece of board with a handle shaped like the battledore in the old game of battledore and shuttlecock. On the face of the hornbook was either a piece of vellum or paper upon which the lesson was inscribed. This was protected by a sheet of translucent horn. This protection was of course necessary to keep the lesson from the possible stain of a pair of dirty little hands, as the hornbook was passed about from child to child. This hornbook of the seventeenth century is an excellent example (Figure 1). It has first the cross, then the alphabet in small letters, the vowels, and then the capitals. Below these are combinations of the consonants and vowels, then the Exorcism and the Lord's Prayer.

The place of the hornbook in the mediæval curriculum is indicated in this picture reproduced from the Margarita Philosophica, written by Gregorius Reisch, and printed in 1504 (Figure 2). This little picture represents education at that period, and shows the teacher who is to conduct the boy to the heights of the Tower of Knowledge handing him a hornbook. The hornbook has upon it the letters of the alphabet, and if the boy masters these letters he will be able to enter the tower. The door through 
which he must pass is called "Grammar" and the first master under whom he studies is Donatus, who lived in the fourth century and who wrote a simple elementary grammar upon the eight parts of speech. Then the student goes up a flight of stairs and studies his large Latin grammar under Priscian who lived in the sixth century. After the next flight he takes his arithmetic under Boetius, his rhetoric under Cicero and his logic under Aristotle; climbing higher he studies astronomy under Ptolemy, geometry under Euclid and music under Pythagoras, and has now mastered the trivium, or three language studies, and the quadrivium, or four science studies. Finally he completes his education with moral philosophy under Seneca, natural philosophy under Pliny, and last of all theology under Peter Lombard. Thus you see what an important part the hornbook played in education at the beginning of the sixteenth century,- that of the key to unlock all the treasures of learning.

Although there are no hornbooks extant that I know of which are earlier than the sixteenth century, there is evidence that the hornbook was used before then. I happen to have in my library an arithmetical manuscript of Sacrobosco, dated about 1400, in which we come unexpectedly upon the picture of a hornbook. The monk who was copying this manuscript evidently became tired of Sacrobosco and his learning and so he made a little picture at the bottom of the page. This picture is a rather crude drawing of a school-room. We see the schoolmaster in his gown, and he is holding up before the pupil a hornbook on which are written not the usual alphabet but the Arabic numerals (Figure 3).

At the same time that the hornbook flourished, primers, or A B C books, were used more or less. Earlier than any hornbook which I have been able to discover is this first page of an A B C book in manuscript, written about 1370 . It will be noticed that this begins with the cross, followed by the alphabet. 


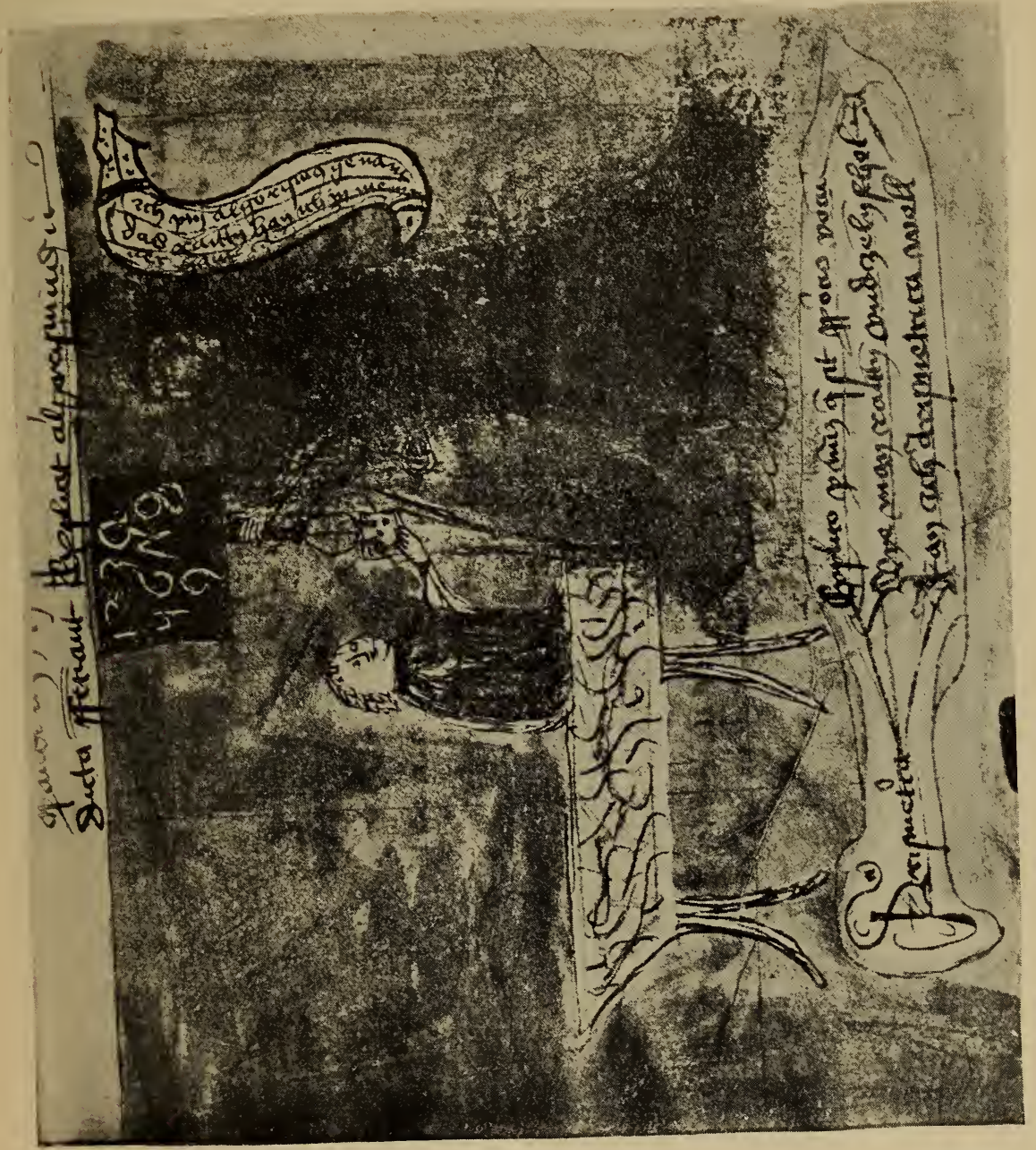

œ 


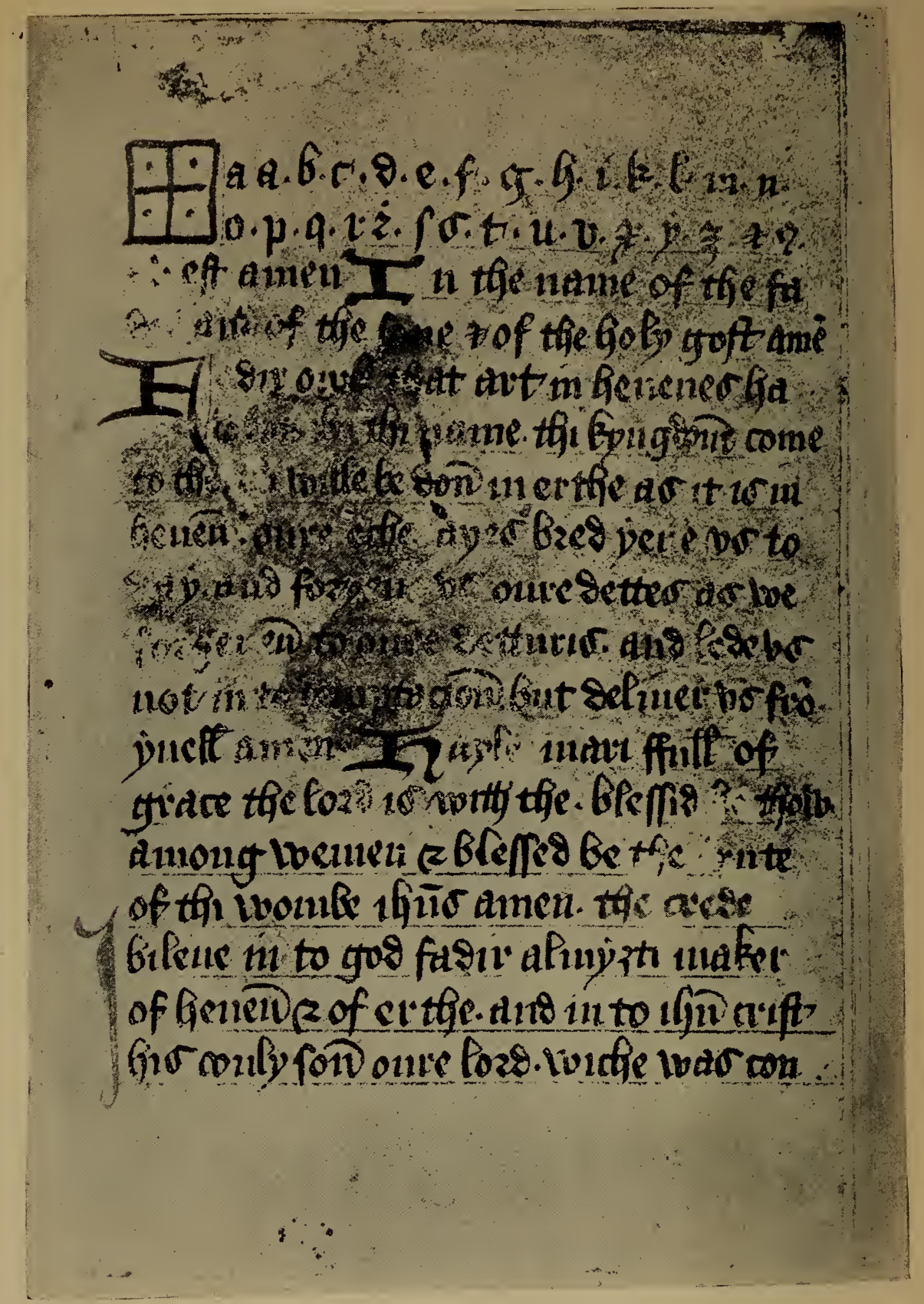

Figure 4 
The alphabet indicates the early period, for, although the first letters are English, the last half dozen are Saxon. Then follow the Exorcism and the Lord's Prayer, the Hail Mary and the Creed. This general order was much the same as the lesson upon the hornbook. The top row of the hornbook, by the way, which commenced with the cross, was called the "criss-cross row," and the pupil was expected to cross himself when he began his lesson. The Exorcism was used with the idea that the average boy was so full of the devil that he needed the proper formula constantly at hand to free him from Satan's wiles (Figure 4).

The next specimen illustrated is the only manuscript hornbook which I possess. Its date is probably about 1700 and it is particularly quaint (Figure $5)$.

It is rather remarkable that so few original hornbooks are extant; the British Museum has only three, and the Bodleian Library at Oxford one. There are several single specimens of hornbooks in private libraries in America, including those of the following gentlemen: Mr. J. P. Morgan, Mr. W. O. Field, and Mr. Alvin Krech of New York, and Mr. Frank B. Gay of Hartford. These are all English hornbooks. I myself have been so fortunate as to pick up from time to time twenty-four specimens of the hornbook. The best examples have been found in England. Shakespeare doubtless learned his letters through the medium of the hornbook. In "Love's Labor Lost," he says:

"Yes, yes, he teaches boys the Hornebook.

What is ab spelled backward with the horn on its head?"

There were many variations from the conventional type of hornbook mentioned above, and some of them are here reproduced. One for instance, is a kind of double hornbook (Figure 6). Undoubtedly the alphabet and the rest of the lesson were originally 
upon one side, but that has been lost. Upon the reverse side is the abacus, the primitive device for counting and making change which is stiil used throughout the East. This particular hornbook is especially interesting because it was used in the famous Blue Coat School in London.

The next illustration is that of an old leather case used for the hornbook, but the lesson which it formerly held has evidently been lost for many years (Figure 7).

The next hornbook shown is one made of wood bound in leather. On the back is a picture of Charles II on horseback, and it is undoubtedly of his period. The elaborately carved English oak which was used as a frame for this next hornbook suggests the richness of the Elizabethan period from which it dates. This specimen lacks the handle (Figure 8).

All hornbooks were not made of wood covered with horn, but no matter what was the material used, they were called "hornbooks." The several varieties in my collection include one of brass which is of English origin (Figure 9), dated 1664 . It will be noticed that this is of the battledore shape, but the next illustrated (Figure 10), which is of copper of a later period, 1729, is a departure from the conventional form.

Another specimen is called the "Golden Hornbook," as its letters are printed in gold. It is of the seventeenth century, and is the only one I have which was made in Germany. It came from Nuremburg (Figure 11).

The next specimen shown, which unfortunately lacks the handle, is a little device of metal intended to carry the child somewhat further than the alphabet, introducing him to all possible combinations of two letters. Its date is probably about 1730 (Figure 12).

A mould for a hornbook is also exhibited. This undoubtedly was considered a prized possession by the fortunate children who had it, for it was used to 


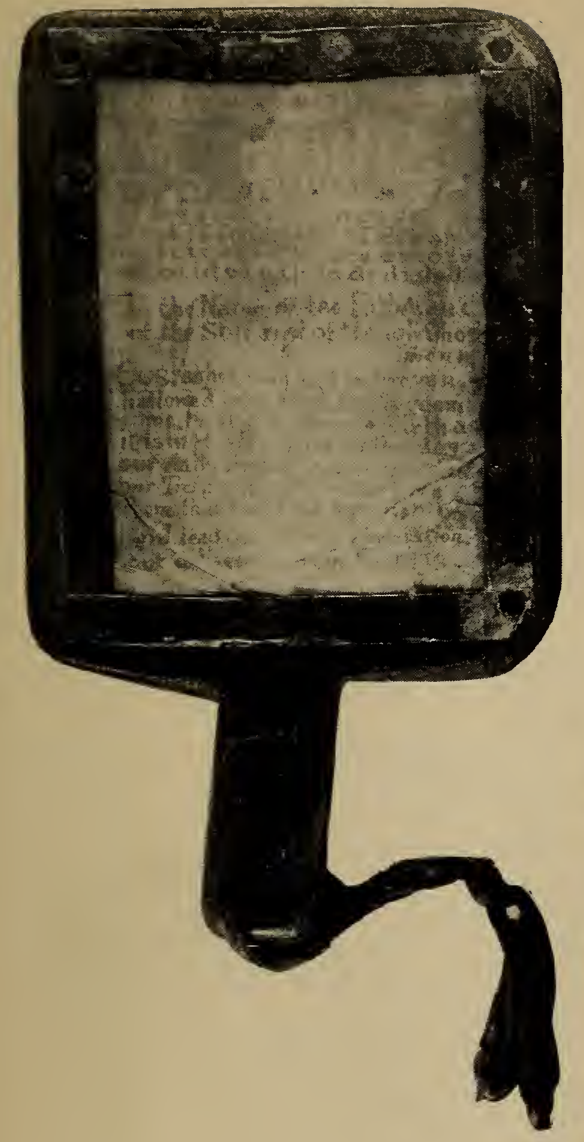

Figure 5

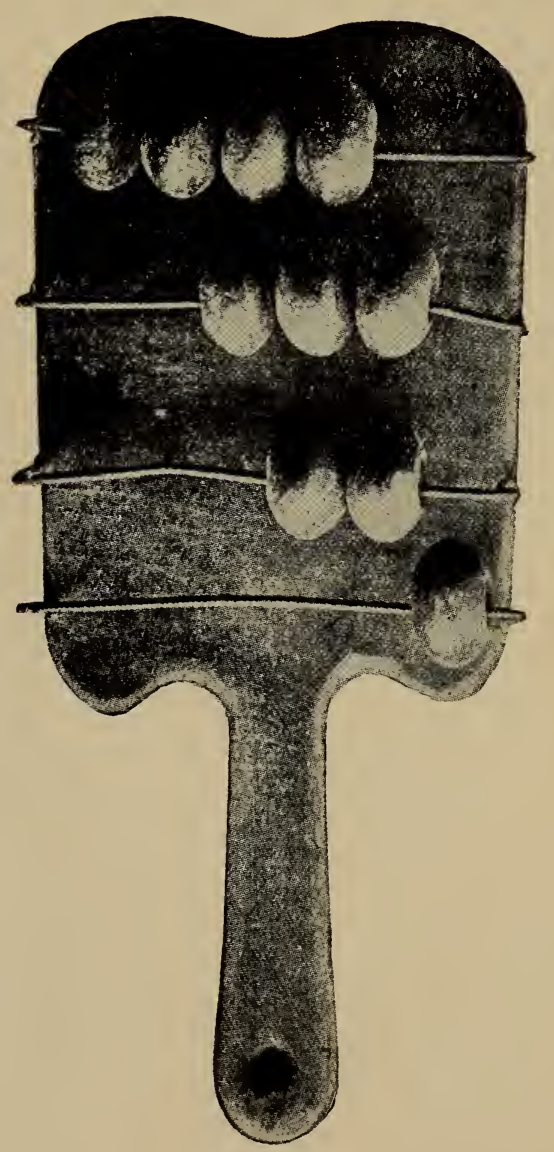

FiguRe 6 


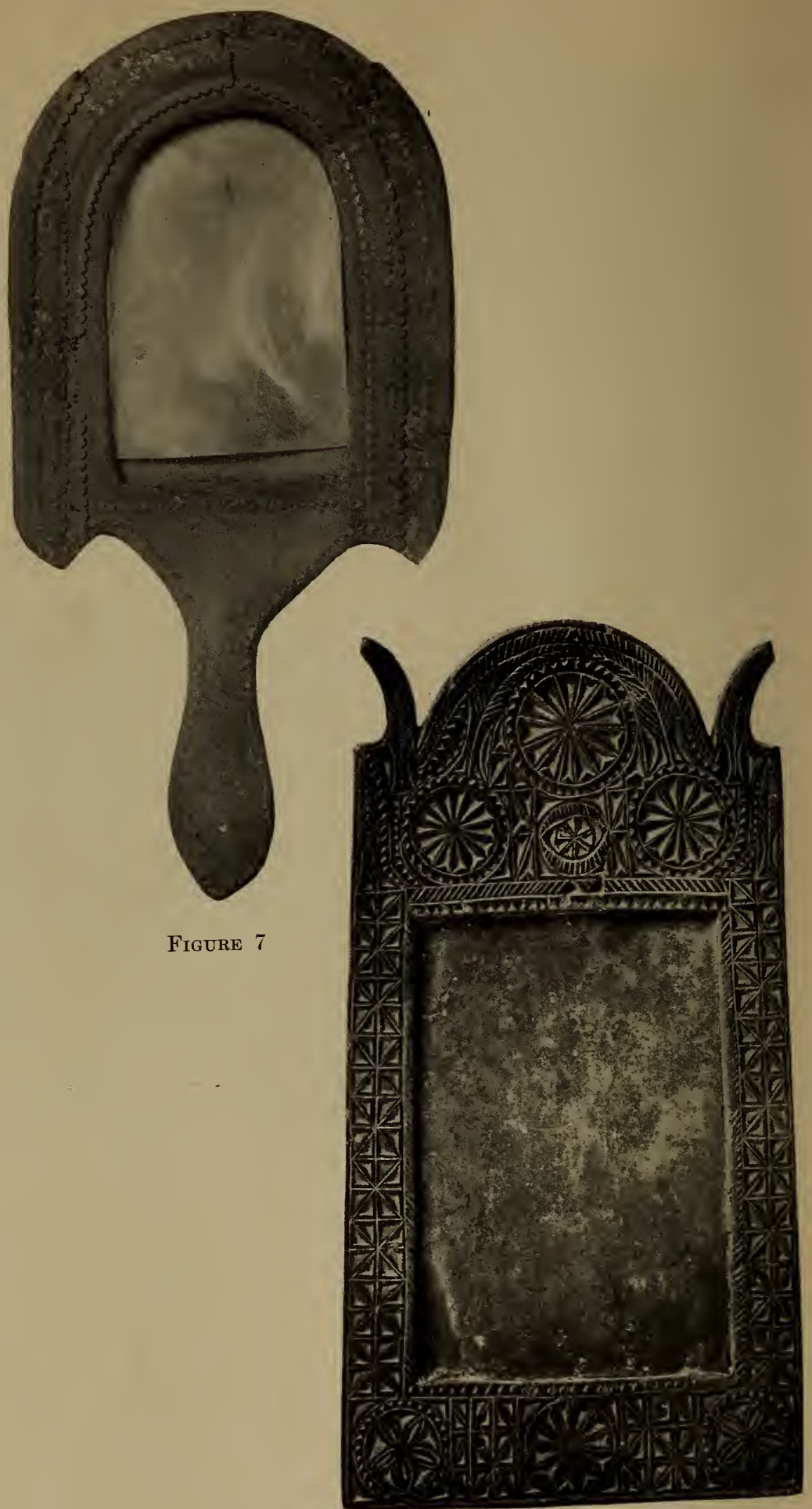

Figure 8 
make a sort of ginger-bread hornbook (Figure 13). About this type of hornbook Matthew Prior, who died in 1721, had this to say:

"To Master John the English Maid

A hornbook gives of ginger bread

And that the child may learn the better

All he can name he eats the letter."

The next hornbook illustrated was made when paper had become cheaper, for it is entirely of cardboard. It is of English make and probably dates from about the middle of the eighteenth century. It still has the handle and the essential form of the hornbook and has preserved the "criss-cross row" as a heading (Figure 14).

So much for hornbooks in general. But we are interested especially in the hornbook in America, and to what extent do we find that hornbooks were used in this country? There is ample indirect evidence to the effect that the hornbook in the colonies, as in the old country, was the favorite device for starting children upon the ladder of learning. The Pilgrim Fathers, of course, came from Holland, and at that time the hornbook was the prevailing method of teaching children there. The Dutch were such clever handicraftsmen that we find many of the early English hornbooks were actually made in Holland. In a little Dutch catechism in my possession is a picture of a school-girl with a hornbook attached to her side-showing a certain regard for feminine education in the Holland of the sixteenth century that we cannot but respect. Whether the Pilgrims actually brought any hornbooks to this country or not I have never been able to discover, but it is a safe inference that they were careful to provide hornbooks for the young Brewsters and Aldens. Considering the Puritan settlers, we have even more reason to be quite sure that such men as Endicott and Winthrop, when they came to Salem 
and Boston, brought the hornbook with them. The Puritans came from parts of England where they were accustomed to good grammar schools and where the hornbook was the basis of learning. So much for the indirect evidence to show that the hornbook was the method of teaching children to read in the colonial days of New England.

The first actual mention which we have of a hornbook in colonial records is this bill which Charles Lidgett made out for cash paid to his wife in 1678 . Among charges for Bibles and other things we find "For horning book and papr 8 d." (Figure 15.) I am indebted to Mr. Worthington C. Ford for this copy of the original bill. The earliest known mention, therefore, that I find of a hornbook in America, is 1678. In the diary of Samuel Sewall (Mass. Hist. Soc. Coll., ser. 5, vol. 5, p. 344), is this entry under date of Apr. 27, 1691:

"This afternoon had Joseph to school to Capt. Townsend's mother's, his cousin Jane accompanying him, carried his hornbook." We scarcely wonder that his cousin Jane accompanied the young man, for we should not consider him of kindergarten agehe was not quite three years old. In the records of the Old South Church for 1708 is the entry, "Paid $1 £$ $10 \mathrm{~s}$. for horns for catechising," and there is a reference to hornbooks in the Winthrop letters, 1716 , showing that there was a custom of sending hornbooks as presents to children. (See Alice Morse Earle's "Child Life in Colonial Days," p. 122).

Some of the files of early newspapers in the Antiquarian Society have been searched to find if there were any advertisements of hornbooks. Several references to them have been found, commencing in 1727 when Andrew Bradford twice advertised in the American Weekly Mercury "Hornbooks for sale." He repeated this in January, February and March of 1730 , and had an advertisement of the same kind on August 29, 1734. Bradford died in 1742 and 


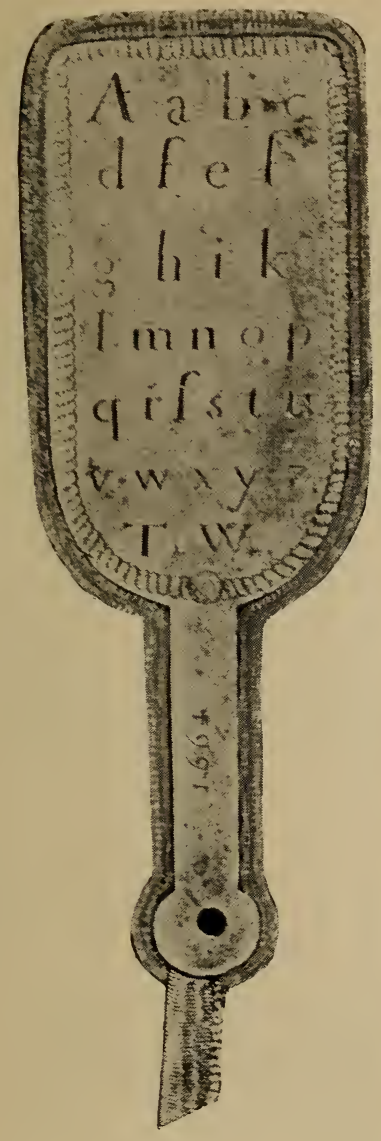

Figure 9

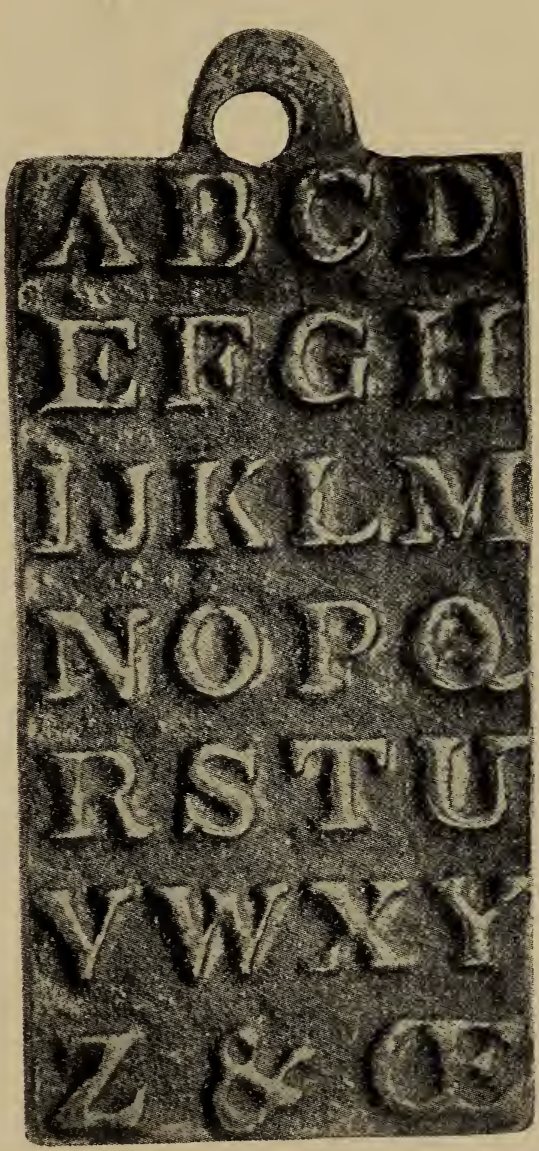

FIgURe 10 

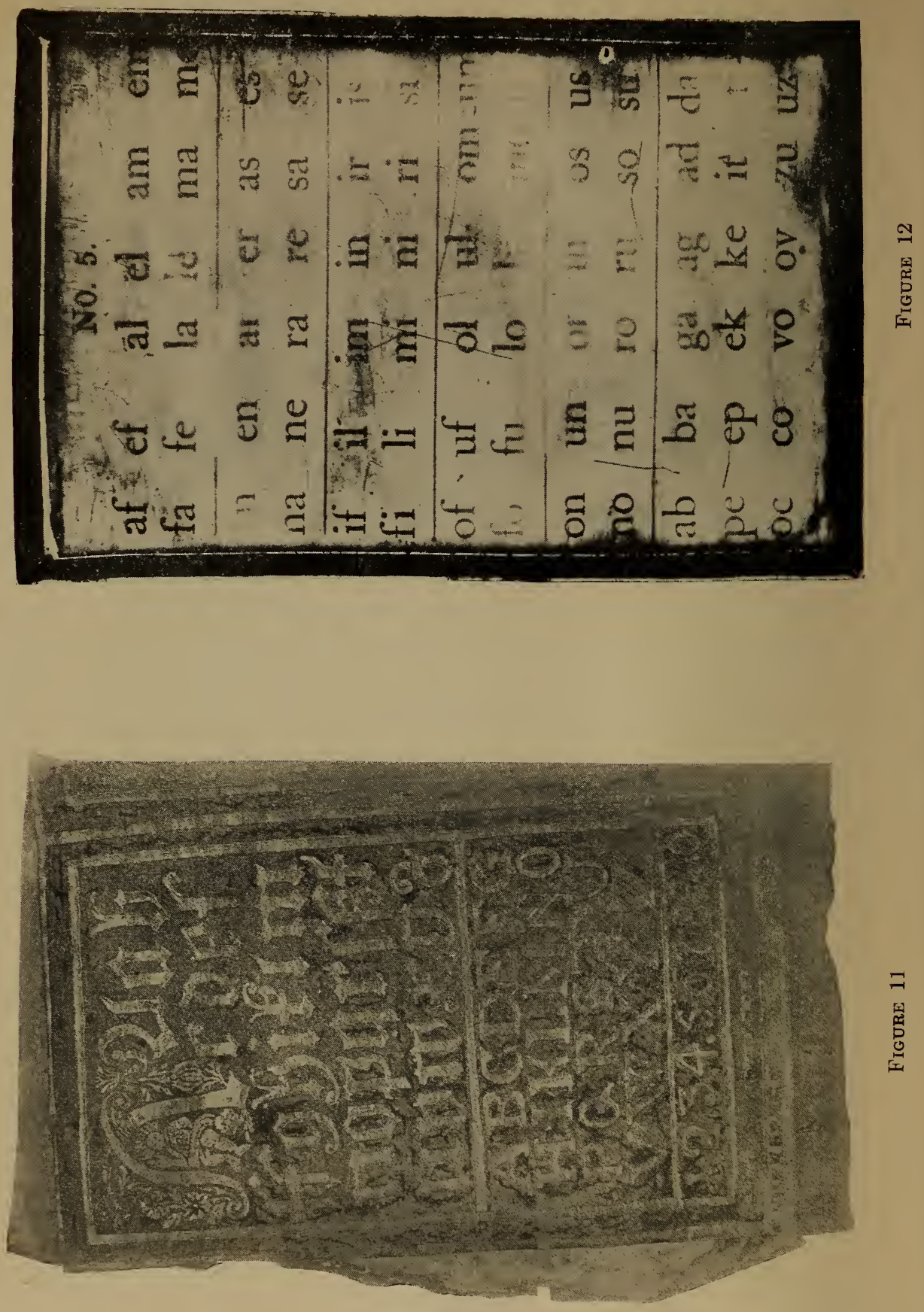
we find his widow, Cornelia, even more enterprising, for she advertises in that year "Hornbooks for sale" three times in February, and again in April, May, June, July, August, and October, and she keeps it up in 1744, in 1745 when her advertisement appeared fifteen times, and in 1746 when it was inserted ten times. Not alone in New England do we find this proof of the use of the hornbook in colonial days. In the Pennsylvania Gazette of December 4, 1760, there is an advertisement of "Primers, Gilt Hornbooks, or Plain Hornbooks." In the South, too, I discovered similar advertisements in papers published both in Charleston, S. C., and in Georgia.

It seems rather strange that with all the hornbooks that must have been used here in the eighteenth century, it has been possible to obtain so few copies. I made a very thorough search myself through South Carolina and Georgia, hoping that I might get track of some of them, but without success. In August 1912, I wrote an article in the Independent on hornbooks and hoped that I might discover in that way people who had hornbooks among their family archives and who would be glad to dispose of them. The only thing that this article brought forth, however, was a letter from the editor of a Minneapolis paper, who said that many years ago an Englishman for whom he had done some service told him that he had nothing to give him but a hornbook which had been in the family for many years. He sent me a photograph of this hornbook, which was badly broken. He did not wish to sell it, and, as it was of English make and almost an exact duplicate of one already in my collection, I was not anxious to acquire it.

Most of the hornbooks that were used in the early days in this country were undoubtedly imported, but I am able to show what is very likely the oldest hornbook made on this continent. It is a Mexican hornbook, probably of the early seventeenth century (Figure 16). It is made entirely of wood, and the 
painted illustration represents the Holy Child Jesus holding up a globe surmounted by a cross. The alphabet is preceded by another cross, as was the fashion on all hornbooks.

Except for this Mexican hornbook I know of but five original hornbooks found in America. One of these, unearthed in Guilford, Conn., is now the property of Ex-Governor Morgan G. Bulkeley. It formerly belonged to Mary Hart, who was a granddaughter of John Hart, the first graduate of Yale College. It is probably of English make since it is exactly like an English hornbook which I possess. In Rhode Island also Mrs. Alice Morse Earle discovered some years ago a hornbook of English make. This is a duplicate of the one which I have described of the reign of Charles II with his picture stamped upon the leather at the back.

Then there are two ivory hornbooks in this country. One of them I purchased myself at Libbie's auction room in Boston several years ago (Figure 17). I have been anxious to trace its history so as to find out whether it is of American origin. There is a rumor that it came from the old Gilman family in Exeter, but I have not been able to verify this. The other ivory hornbook is the property of an old New York family and is thought to have been made in Scotland. The last of the five hornbooks found on this continent was discovered in Princeton, N. J., and this is really an American hornbook (Figure 18). It must have been made in the early part of the last century for the lesson is taken from the Philadelphia Primer, which was published in 1821 by Johnson. By removing the little wooden slide, various reading lessons could be inserted under the horn. This next exhibit is a sort of kin to the hornbook, reading lessons pasted on board. This particular specimen was used in the old Erasmus Hall School of Flatbush, Long Island. Such reading lessons were used largely in the Lancastrian schools, which flourished here in the first 

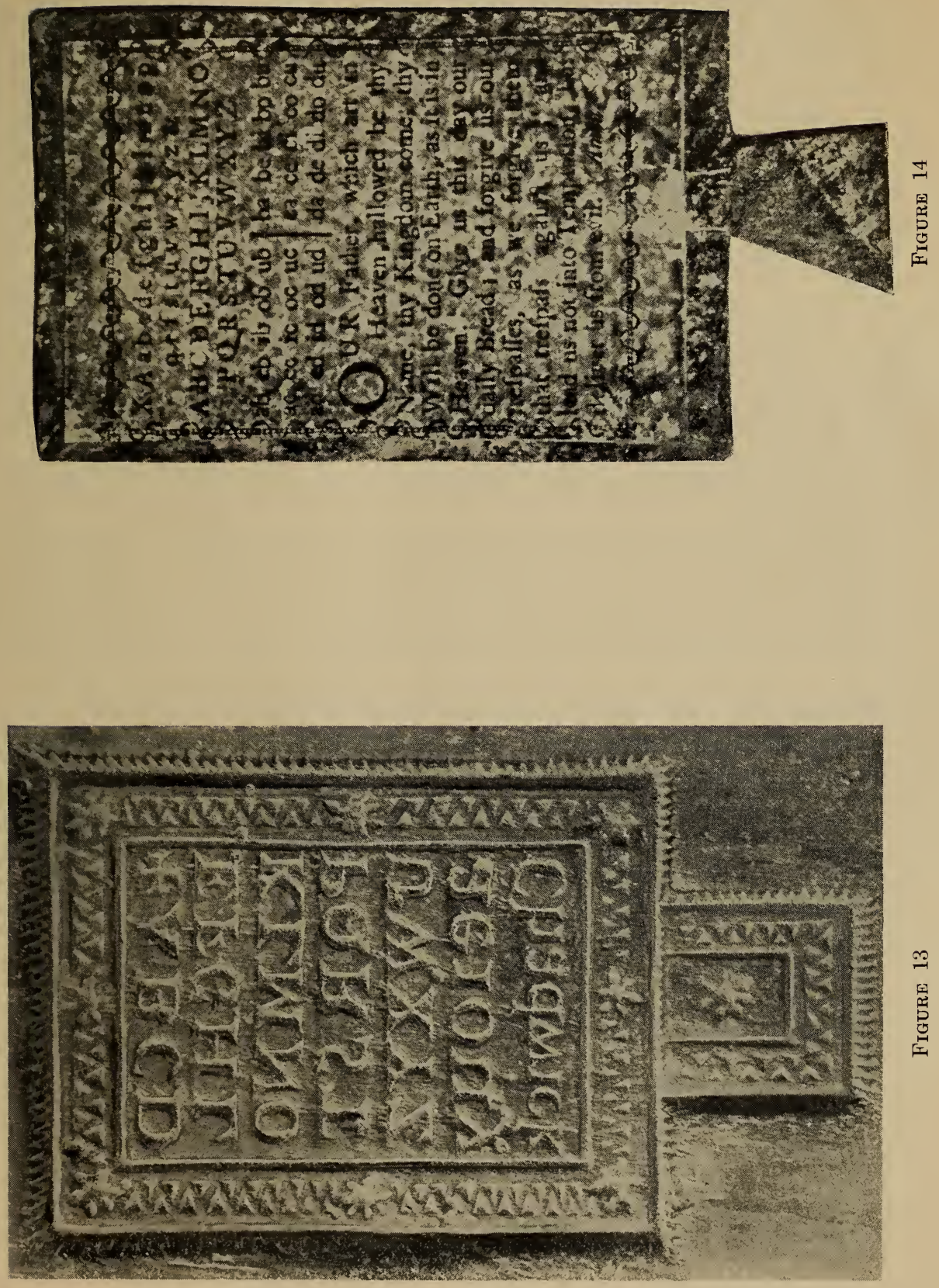


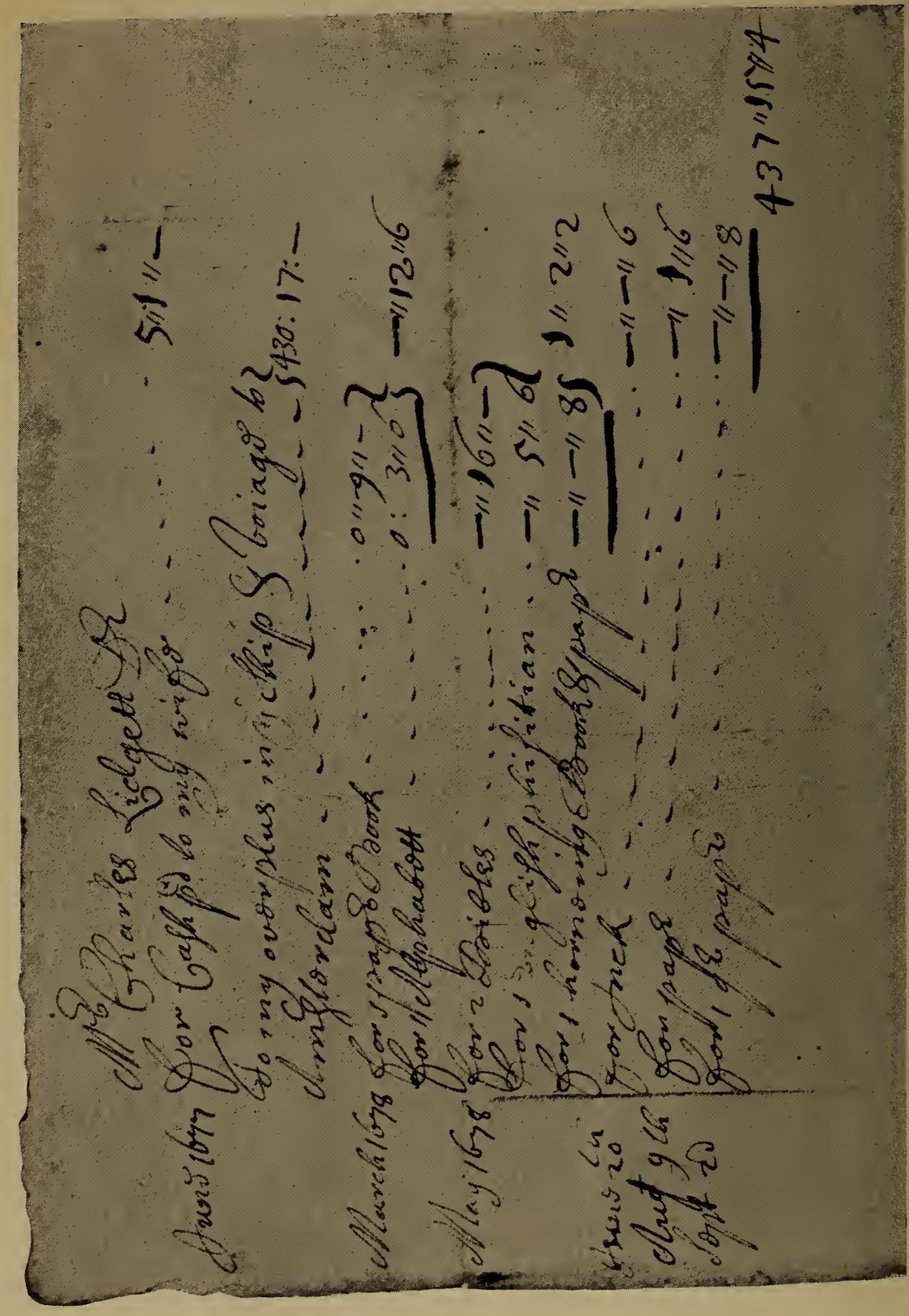

告 

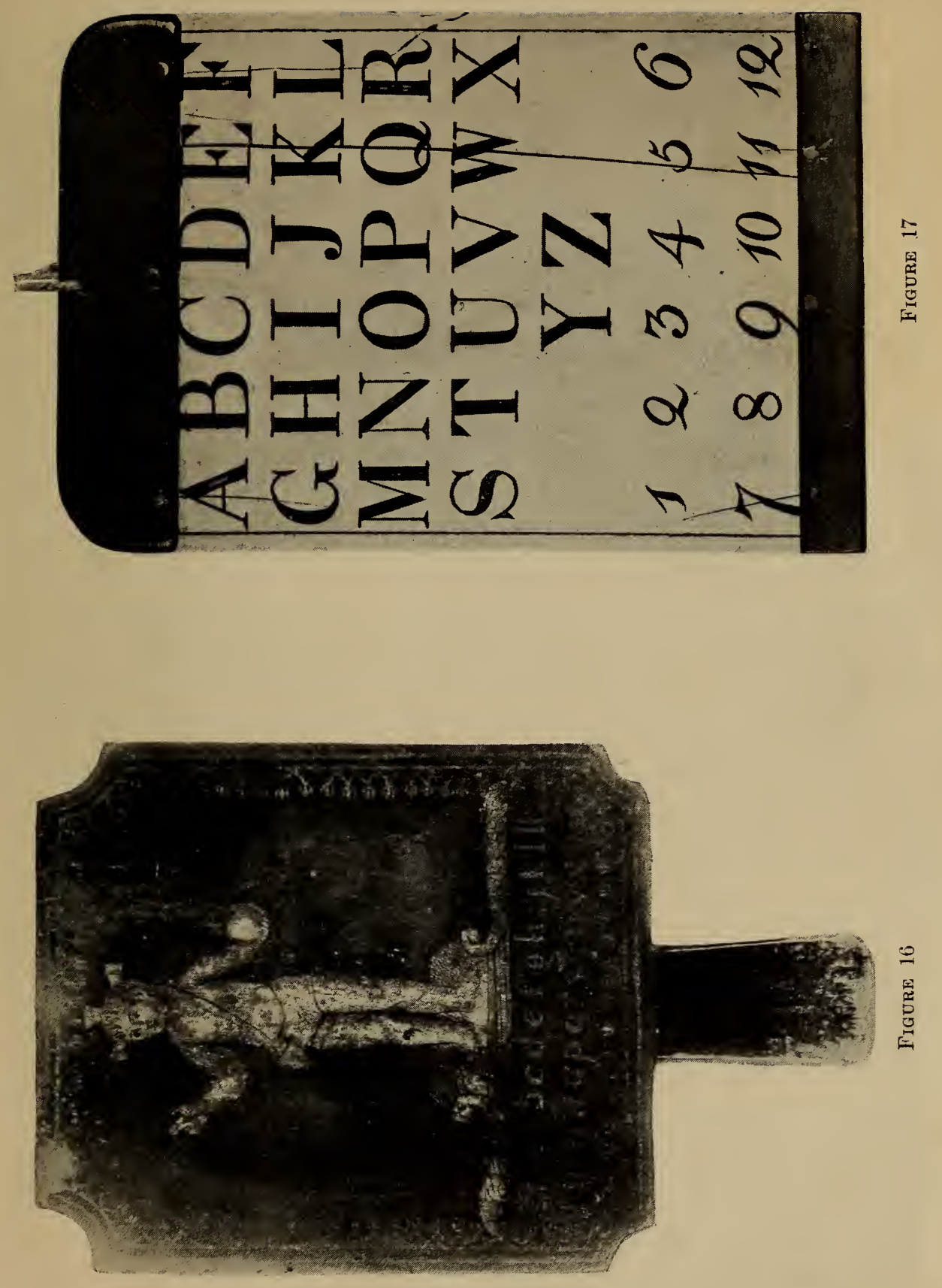


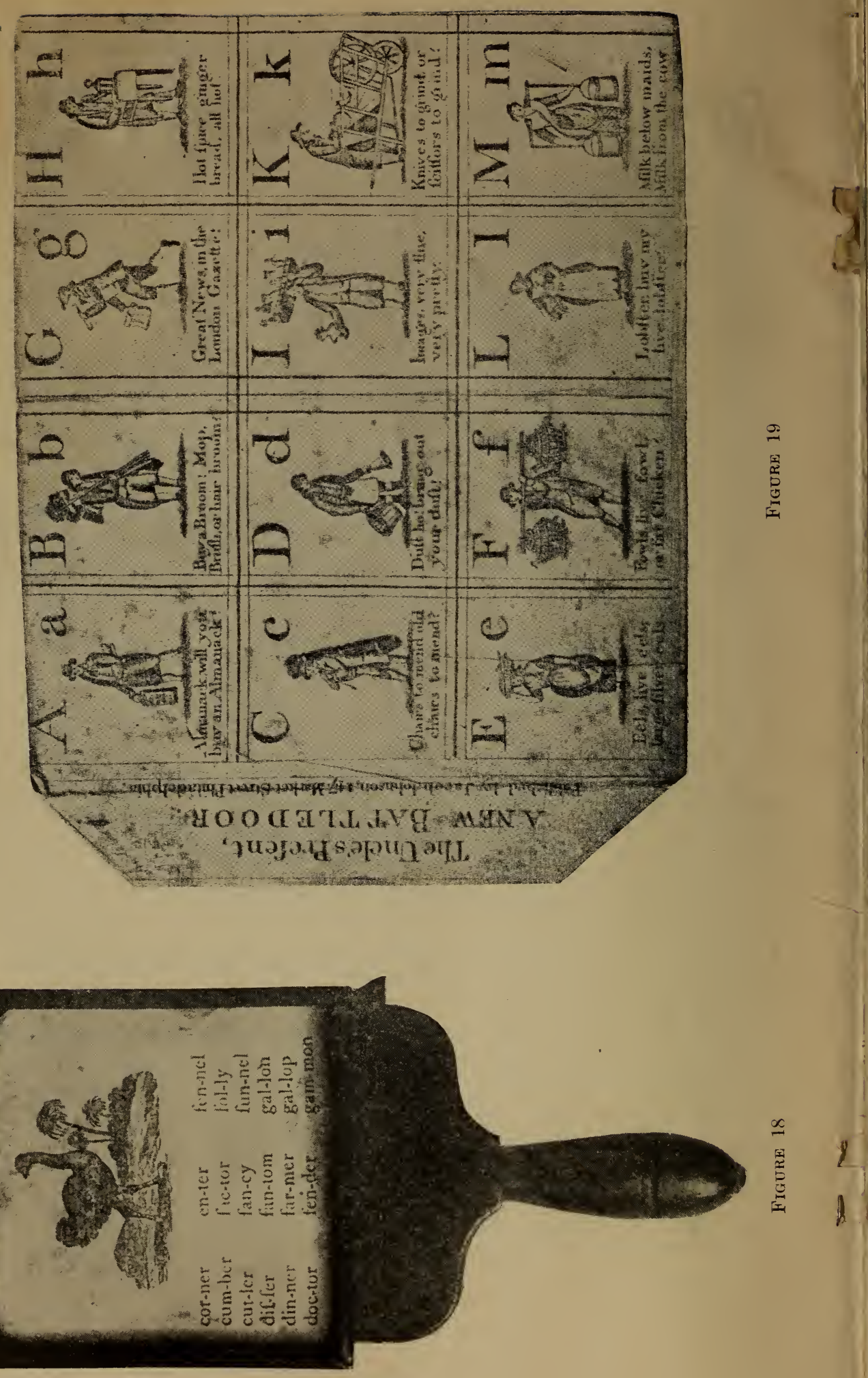


quarter of the nineteenth century, and which were based upon the idea of having the pupils do a large part of the teaching.

Down through the centuries the hornbook gradually modified its form, finally losing its handle. With paper and print more available, cardboard A B C's took the place of the hornbook. The last illustration shown is that of a battledore book, which is obviously an outgrowth of the hornbook (Figure 19). It is to be regretted that so few specimens of hornbooks have been discovered in this country, but the evidence of their use in colonial days is unmistakable. It must be admitted, however, that most of those used here were imported from Europe. 

Syracuse, N. Y.

Stockton, Calif. 
MMTHSONIAN INSTITUTION LIBRARIES

SMITHSONIAN INSTIUIIIIIUU! IUII

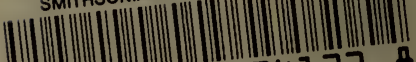

3908800424723

chm Z1033. 18 P63 19162

The hornbook and its use in Amerca

\section{$B$}

The horn 